\title{
Sustainable development of climate change resources: About recycling of water resources in Maple Park, Taichung, Taiwan.
}

\author{
Chang-Hsien $\mathrm{Hsu}^{1}$ Chiu-Yu Hung ${ }^{2}$ \\ ${ }^{1}$ Department of Business Administration, Asia University, Taiwan \\ ${ }^{2 *}$ Department of Business Administration, Asia University, Taiwan
}

\begin{abstract}
Water is an essential substance in the global environment that sustains the functioning of all ecosystems. In fact, the demand for water resources should not be limited to human activity systems. In terms of sustainable development of the environment, the distribution and development of water resources need to expand to the needs of other ecosystems on the planet. Taiwan is surrounded by the sea and is a typical island-type economic country. However, due to the young geology of Taiwan, the terrain is too large and undulating, so that the rainwater quickly flows into the ocean and is difficult to store. Taiwan has an average of 2,500 $\mathrm{mm}$ of rainfall per year[1].The rainfall in Taiwan is more than 2.6 times the global average, it is a country with abundant rainfall. At the same time, there is also a crisis of water shortage. Due to the narrowness, the steep mountains, and the heavily rain of typhoon, it quickly flows into the sea. So that even if the rain is more and more in Taiwan, it will not ease the problem of water shortage. Therefore, the application of circular economy and water reuse is more important. This study takes "Flood detention pond in Maple Park" as the object of discussion. Exploring how the Taichung City Government used the ecological park to achieve the role of reservoirs for flood detention and disaster prevention. In addition, how to use water resources efficiently to achieve sustainable development has become a major issue in modern times.
\end{abstract}

\section{INTRODUCTION}

Facing a sharp rise gas concentrations in global greenhouse. The issues that related to energy conservation and resource reuse are re-emerging in countries. Also successively adopted the 21 st Century Agenda and the Rio Declaration at the "Earth Summit" to support for climate change and related countermeasures. In 1979, the first World Climate Conference held by the National Meteorological Organization in Geneva, Switzerland. This is the first international conference of the United Nations to promote global. The conference determined important conclusions: Climate affects humans, and humans also influence climate. Climate change is not only a scientific issue, but also an important factor influencing human society and economic development. In 1997, the "Kyoto Protocol" was formulated. The goal is nothing more than controlling the amount of greenhouse gases in the atmosphere and keeping it at an appropriate level. So as not to cause further serious harm to humans.

Earth's water resources are limited. Must be used more efficiently, even recycling, in order to make resources sustainable. The water technology paradigm of Israel and Singapore is a model that Taiwan can refer to. Israel has more extensive underground to collect domestic sewage and develop unique "drip irrigation" technology. Buried pipeline at the bottom of the crop to deliver water directly to the roots of the plant, reducing unnecessary water evaporation. Create an agricultural miracle in the desert.

Water resources are also extremely poor in Singapore. Among them, the world-renowned fresh water uses advanced membrane filtration technology. Filter out impurities in the sewage and purify it by ultraviolet sterilization that make it clean and drinkable reclaimed water. But rich in lake of water. It's deserves that Taiwan to follow this as an example.

As can be seen from the above, environmental issues are particularly important for island-type country "Taiwan". Taiwan belongs to the subtropical climate zone. The average annual rainfall is over 2,500 $\mathrm{mm}$. But $80 \%$ of the rainfall is concentrated in the rainy season from May to October. Coupled with the steep terrain, more than $70 \%$ of the rainfall flows into the sea. Taiwan ranks 20th among countries with global water shortages. As soon as it didn't rain, Taiwan immediately developed a drought, but when it rains, it will flood[2]. It can be seen that the "resource cycle" is already an inevitable important issue or one of the solutions. The promotion and development of sustainable development of resources by governments and enterprises is only a matter of time. Therefore, this study takes "information sustainable development" as the main theme. And according to how the government implements "resource reuse" to explore related issues and implementation. In

Corresponding author: taylor@wellball.com.tw 
this way, we try to understand how much the government can remedy the environment in promoting the implementation of related issues.

\section{Water Resources and Sustainable Development}

The UN's World Commission for Environment and Development held the Conference on Environment and Development in Rio de Janeiro, Brazil in 1992 and passed Agenda 21, which discuss global climate change and sustainable water resource and make several engineering blueprints for sustainable development that will have a direct effect on the future living environment of humankind. Besides, in the latest environmental index report of sustainable development which issued by Organization for Economic Cooperation and Development (O.E.C.D.) in 2001, there are also some changes and updates regarding the index of water resource, proposing several indexes for the sustainable development of water resource, for example, irrigation area, using strength of water resource, the supply price of water resource. Also, historical record of legal water withdrawal permits, effective rainfall in dry season, excessive water intake shorten the length of river, daily condition of water supply and need, etc.

Hence, how to implement sustainable development and resource sustainability is the common concern of all the countries at the moment.

For the issues of water resource, energy, health, poverty, agricultural resource, creature diversity, the United Nations held World Summit on Sustainable Development in Johannesburg, South Africa in 2002 to discuss the issue of carrying out the sustainable development under the globalization trend, hoping to real implement the sustainable development.

In 21 st century, Taiwan will follow the development of technology and become a technology island. And the water resource is the key to develop the national overall business. Due to the global climate change, it is hard to predict the condition of available water. By promoting the belief of sustainable development around the world, the water resource management, water reservation and water resource coordination should be paid more attention instead of focusing on water resource development only to achieve the goal of sustainable water resource use. In order to supply water in high demand and stabilize the supply in the future, the other water source development and plan should have wide and modern supply policy on water resource. Enhancing supply-side and improving the performance of the cycle of water resource is also needed. By the evaluation which is available in economy, technology and acceptable by social environment to meet future demand. For the sustainable development of water resource, Taiwan has created new water resource management system, integrating and promoting by Environmental Resources Department and coordinating international development trend which included policy and regulation, education training, environmental management, resource protection, ecological conservation, pollution prevention and ecological efficiency to do a special project and promote the job of sustainable development[3].

\section{Implement and Carry Out}

Due to Taiwan's geographic location, every year have natural disasters, like plum rain season, typhoon and earthquake. And the cost of disaster loss repair is higher than other countries. $2000 \mathrm{~mm}$ (millimeter) average annual rainfall flows into the sea rapidly because of the landform. Uneven seasonal distribution and deficient in reservoir deposit cause the household water which store in Taiwan main island lower than global average standard.

Maple Valley Park, a large city park with the design of low elevation greenbelt, is located in the most exclusive and expensive area in Taichung and have the function of environmental greenification and air purification. When the typhoon hit Taichung, Maple Valley Park plays an important role in adjustment and storage. The estimated detention volume is about $200,000 \mathrm{~m} 3$ (cubic-meter) and it can reduce the street flooding effectively. Being the first multi-target benefit park which has the function of storage and landscape, the completion of Maple Valley Park is not only a reliable guarantee for the citizen of Taichung, but also a thought transformation in disaster prevention. Also an engineering indicator for the development plans of flood control facility in the future, all the design concepts could become the model of relative engineering afterwards. Below are the steps:

\section{Rain \\ Ecological detention pond}

\section{Irrigation system, Outdoor green space, Lake viewing, Restroom water use}

figure 1. Water resource circulatory system of detention pond

Accordingly to figure 1[3], we can understand that Maple Valley Park use detention pond to utilize rain effectively and improve the regional drainage. Installing geotextiles on the bottom of detention pond use gabion to protect the slope and set 3 wet wells and 2 inlet wells in the middle, this area and neighborhood could be prevented from flooding. And the detention pond, which can contain $200,000 \mathrm{~m} 3$ (cubic meter) water volume is used to irrigate the plants in the park and connect with the surrounding drainage channel level. It is planned to start the control gate and water level sensing device in 2013. When the water level of Chauyang River rises and can lead to street flooding near the river, the gate will be opend via remote control system and guide the water which flow from Taiwan Avenue to Chauyang River's sewage to store in Maple Valley Park temporarily and avoid bursting the banks and covering the house. Landscape ecology, exhibition, environmental afforestation and temporary detention pond are included in the engineering. 
To minimize the impact of urbanization on existing flood control facility, detention pond has become an essential facility on modern land development, which can improve the street flooding before development and reinforce the multiple functions of detention pond, such as ecological education, rainwater recycling, sport and recreation, outdoor display square and community settlement. Hoping the transforming thought of detention pond could help implement the idea of national spatial development, ecology and environmental protection.

Regarding the sustainable resource development, the most difficult part for the government is the comprehensive planning. The first step is to reduce the extra burden on the natural ecology and then give back to the nature which is more imporant than other things. Taichung Maple Valley Park uses the detention pond to prevent the city from flooding and fully utilize the water resource through the circulatory system and combine the concept of natural symbiosis and sustainable development. Through the construction methods to build the most energy saving space and achieve the goal of green cycle and resource reuse.

In order to reduce the impact of urbanization on existing flood control facilities, detention pond has become a necessary facility for land development, and then improve the pre-development road flooding, and deepen the detention pond both ecological education, rainwater recovery, sports recreation, outdoor performance Plaza and community neighbourly and other multiple functions, and integrate local characteristics, We also look forward to the implementation of the ideal of land development and ecological and environmental protection through the detention pond.

In terms of sustainable resources development, the most difficult thing for the government to implement is the overall planning. It is necessary not only to avoid adding unnecessary burdens to the natural ecology but also to expect to be able to give back to nature. Taichung Maple Graden use the detention pond prevents flooding in the city, and at the same time, it has a complete circulation system for water resources to fully utilize it, combined with the concept of natural symbiosis and sustainable development, and effectively creates the most energy-saving environment through construction methods. The part that is reused with resources is also perfect.

\section{Conclusions}

Under the ultimate concept of pursuing sustainable development, water resources development must also focus on how to reconcile with nature. At the same time, it also has the obligation to maintain the existing ecological environment. Because the ecosystem is very fragile, once it is destroyed, it will be difficult to be recovered in a short period of time. The restoration of the appearance may even end, and it must be treated with caution. In addition to the establishment of public facilities, how to make good use of water resources is also worthy of discussion. It should avoid improper water resources development and adapted to the principle of sustainable use. Without water, human beings can live for three days at most. We know how important water is to us.

Now the developed countries in the world are paying attention to this issue and investing a lot of money and resources in building water resources protection. The government also continues teaching people about the recycling, environmental protection, and recycling of water resources has greatly assisted the recycling of the entire water resources. From the disaster caused by heavy rain in recent years, the reservoir cannot be tanked, but it has to discharge it several times to regulate it. We should try to store and use this rainwater effectively for the planet to continue operating. Although this process is expensive but it is definitely worth investing.

Taking Maple Garden as an example, it is obvious that environmental awareness and ecological engineering methods have catalyzed the change of concepts and quality of engineering planning, design, construction and supervision in Taiwan, and have been combined with the natural environment. Since its completion in 2012, the structure has been stable so far. After many strong typhoon attacks and heavy rain, it has effectively played a role in regulating urban flood detention and improving the flooding of Taiwan Boulevard. Using the existing high-difference terrain and the natural features of the slope, supplemented by the green industry method to improve the application, reduce the interference to the ecological environment, and provide the function of environmental green beautification. Minimize carbon emissions in engineering materials and engineering applications. Nearly 400 trees and 16,000 square meters of shrubs are planted around the lake, increasing the green coverage rate of 28,000 square meters for Taichung City, which will effectively reduce the heat island effect for west Taichung. Maple Garden has become the lung of the city to reducing the heat island effect. The project has the good effect; the green work method increases the friendliness of the environment, and also improves the air quality and reduces the harm caused by air pollution. It also a good place for Taichung citizens' to leisure, as well as free occasional exhibitions of various theme activities for people to visit.

\section{References}

\section{Weng,S,P.\&Yang,C,D.,Establishment of monthly}

rainfall and temperature with a one-kilometer network database in Taiwan (1960-2009) and Its climate estimation application in the future(2015-2039),

Atmospheric Science, 40(4), 349-370(2012).

2. Lu, M, M., Chen, J, J., \& Lin, Y, J.. Changes in the

frequency of extreme rainfall events in Taiwan from

1951 to 2005. Atmospheric Science, 35(2), 87-104

(2007).

3. WRD, Ministry of Economic Affairs.Central Region

Water Resource Office, Water Resources Department, 
Ministry of Economic Affairs, Taichung(2019).

4. De Bruijn, K., and Klijn, F.. Risky places in the

Netherlands: a first approximation for floods. Journal

of Flood Risk Management,2(1),58-67(2009). 